\title{
A LEITURA E A ESCRITA EM MUTAÇÃO: EXPERIÊNCIAS NO MEIO DIGITAL
}

\author{
READING AND WRITING IN MUTATION: \\ EXPERIENCES IN THE DIGITAL MEDIA
}

\section{LECTURA Y ESCRITA EN MUTACIÓN: EXPERIENCIAS EN MEDIO DIGITAL}

\author{
Adair Aguiar Neitzel \\ Taíza Mara Rauen Moraes \\ Cleide Jussara Muller Pareja
}

\begin{abstract}
RESUMO
Este artigo visa problematizar acerca das mutações de leitura que vem ocorrendo na contemporaneidade, haja vista o acesso aos novos suportes de textos, como a tela do computador, tablets e celulares. Trata-se de um olhar analítico, de caráter qualitativo, respaldado nos trabalhos desenvolvidos por Poulain (2012), Petit (2008), Bélisle (2011), Autor (Ano), entre outros, sobre experiências de leitura e de produção vivenciadas pelos licenciandos do curso de Letras da UNIVALI, bolsistas do programa PIBID, em uma escola pública do Ensino Médio de Barra Velha, SC/Brasil. Os instrumentos de coletas de dados foram: portfólios redigidos pelos licenciandos de Letras, bolsistas do PIBID, disponíveis no ambiente Sophia da instituição e entrevista com os alunos do Ensino Médio que participaram da pesquisa. Os resultados indicam: a) a descoberta, por parte dos futuros professores de Letras, das potencialidades do texto literário em meio eletrônico tanto para leitura quanto para produção textual; b) exploração de múltiplas estratégias de leitura em meio digital; c) compreensão do conceito de intertextualidade por meio do romance Grau 26 e da produção de links nos textos elaborados; d) análise do papel do mediador de leitura no processo de formação de leitores.
\end{abstract}

PALAVRAS-CHAVE: Leitura em meio digital. Hipertexto. Formação de leitores. Mediador de leitura.

\section{ABSTRACT}

This paper aims to discuss about the reading mutation that have occurred in the contemporary times, due to the access to new text platforms, such as the computer screen, tablets and mobile phones. It is about an analytical point of view, of qualitative character, supported by the works undertaken by Poulain (2012), Petit (2008), Bélisle (2011), Neitzel (2009), among others, on reading experiences and production experienced by graduating students of the Portuguese Language and Literature course of UNIVALI, scholarship students of the PIBID program in a Public High School of Barra Velha (SC/Brazil). The instruments of data collection were: portfolios written by the undergraduate graduating students of the Portuguese Language and Literature, scholarship students of PIBID available in the Sophia environment of the institution and interviews with High School students that took part of the survey. The results indicate: a) the discovery, by future Portuguese Language and Literature teachers, of the potentialities of the literary text in electronic media both for reading and textual production; b) exploration of multiple reading strategies in digital media; c) understanding of the concept of intertextuality through the romance Level 26 and production of links in the elaborated texts; d) analysis of the reading mediator's role in the reader education process.

KEYWORDS: Reading in digital media. Hypertext. Reader education. Reading mediator. 


\section{RESUMEN}

Este artículo visa hacer reflexiones acerca de las mutaciones de lectura que viene ocurriendo en la contemporaneidad, haya vista el acceso a los nuevos soportes de textos, como la pantalla de la computadora, tablets y celulares. Se trata de un mirar analítico, de carácter cualitativo, respaldado en los trabajos desarrollados por Poulain (2012), Petit (2008), Bélisle (2011), Neitzel (2009), entre otros, sobre experiencias de lectura y de producción vividas por los estudiantes del curso de Letras de la UNIVALI, becarios del programa PIBID, en una escuela pública de la Enseñanza Media de Barra Vieja, SC/Brasil. Los instrumentos de recogidas de datos fueron: informes redactados por los estudiantes de Letras, becarios del PIBID, disponibles en el ambiente virtual Sophia de la institución y entrevista con los alumnos de la Enseñanza Media que participaron de la pesquisa. Como resultados indicamos: a) el hallazgo, por algunos de los futuros profesores de Letras, de las potencialidades del texto literario en medio electrónico tanto para lectura cuanto para producción textual; b) exploración de varias estrategias de lectura en medio digital; c) comprensión del concepto de intertextualidad por medio del romance Grado 26 y de la producción de links en los textos elaborados; d) análisis del papel del mediador de lectura en el proceso de formación de lectores.

PALABRAS CLAVE: Lectura en medio digital. Hipertexto. Formación de los lectores. Mediador de la lectura.

\section{INTRODUÇÃO}

Ce phénomène de désaffection apparente pour la lecture s'est manifesté à un moment de grandes politiques de lecture innovantes. Martine Poulain (2012: 69).

Poulain (2012), em entrevista publicada no livro Les mutations de la lecture, defende a ideia de que estamos passando por um período de mutações que evidencia uma mudança não apenas nos hábitos de leitura, mas também nas relações que mantemos com os diversos objetos culturais e com os valores sociais. A leitura utilitária avança enquanto a leitura fruitiva está perdendo espaço. Ela evidencia que, se há na França uma diminuição de leitura de livros impressos, o mesmo não ocorre nos suportes digitais. Nesse sentido, os novos suportes de leitura - como os livros eletrônicos ou ainda os textos disponíveis em outros meios digitais - representam uma possibilidade de ampliar o universo de leitores. Essa constatação nos permite problematizar que, apesar das pesquisas sobre o número de leitores no Brasil e na França apontarem para uma escala decrescente, há um grande contingente de leitores em outros suportes que não pode ser ignorado, como sinaliza Poulain (2012).

As mutações de leitura ocorrem também no meio impresso. Muitos são os livros que hoje exploram outras formas de escrita, propondo deslocamentos no ato de leitura. Livros como Gran cabaret demenzial, de Veronica Stigger (2007), que rompem com a estrutura formal das narrativas, introduzindo textos inverossímeis, beirando o insano e o cômico. Se a língua é fascista, como afirma Barthes (2002), cabe ao escritor combatê-la com uma proposta que rompa com as convenções, e, nesse caso, beirando o anarquismo. Longe dos discursos tipificados, sua escritura trabalha no revés, abjurando o passado literário.

Essas reflexões sinalizam as mutações que os processos de leitura e de produção vêm sofrendo na sociedade contemporânea, tendo em vista, principalmente, os novos suportes de textos circulantes em meio digital. A universidade pode ser o lugar onde se amplia o cânone 
literário, e os licenciados serão os sujeitos que vão mediar o processo de leitura nos diversos suportes circulantes na contemporaneidade. Assim sendo, esta pesquisa apresenta uma análise de experiências de leitura e produção vivenciadas por licenciandos do curso de Letras da Universidade do Vale do Itajaí (UNIVALI), bolsistas do Programa Institucional de Bolsas de Iniciação à Docência (PIBID), em uma escola pública do ensino médio de Barra Velha, SC, Brasil. O PIBID é um programa da Coordenação de Aperfeiçoamento de Pessoal de Nível Superior (CAPES) que disponibiliza bolsas de iniciação à docência para acadêmicos de licenciaturas para o desenvolvimento de projetos inovadores em várias áreas do conhecimento nas escolas públicas.

O subprojeto do PIBID de Letras, intitulado Leitura em meio eletrônico, objetivou explorar o uso de computadores como uma ferramenta de leitura, visto que essa tecnologia exerce fascínio sobre os jovens. O grupo partiu do pressuposto de que o uso de computadores nas aulas de Língua Portuguesa e Literatura podem tornar a ação de ler mais convidativa, uma vez que os jovens passam horas conectados em computadores, notebooks, tablets e celulares. O projeto visou a exploração das possibilidades de produção e leitura de textos em meio digital para que os alunos do Ensino Médio pudessem ampliar suas percepções sobre a leitura e perceber as funções estéticas do texto literário, aproximando o leitor do texto e dinamizando, assim, as aulas. Por outro lado, abriu novos espaços aos licenciandos de Letras - futuros professores e mediadores de leitura - para que percebessem o computador como uma ferramenta que pode auxiliar o processo de leitura e de produção de textos nas escolas.

No processo de investigação, surgiram algumas questões que ampliaram as discussões, entre elas: Como o leitor em formação se relaciona com o texto literário digital? Os links são aberturas que o impulsionam à leitura ou dificultam? Como que a história da leitura em meio digital se coloca frente à leitura em meio impresso? No que diz respeito à produção de hipertextos, como se constrói a relação entre autor e obra? Quais as competências acionadas no ato de criação de um texto multimídia? As discussões sustentamse nas reflexões propostas por Santaella (2008), a qual afirma que a leitura hipertextual caracteriza-se como uma "leitura em trânsito", ou seja, uma leitura com riscos, pois poderá ser desorientadora ao invés de orientar, se o leitor não tiver a capacidade de construir um mapa mental que funcione como guia de leitura. Silva (2014), ao ser questionado sobre o que é leitura, afirmou que ele entende a leitura:

Como produção de sentido(s) aos signos que veiculam conteúdos culturais. Essa produção, por sua vez, é orientada pela intencionalidade do sujeito-leitor. Nestes termos, movido por um horizonte de compreensão/interpretação, o leitor recria sentidos possíveis a um texto. Costumo dizer que o movimento de leitura envolve movimentos conscientes de destecer e retecer sentidos (ideias) a partir da interação leitor-texto. (SILVA, 2014, p. 117).

Desse modo é que os estudantes efetuaram as leituras em meio eletrônico e em impressos, criando e recriando sentidos às leituras realizadas, possibilitando um retecer de sentidos em textos escritos nos dois formatos. 


\section{PROCEDIMENTOS METODOLÓGICOS: CONTEXTUALIZAÇÃO DA PESQUISA}

Esta pesquisa foi desenvolvida na Escola de Educação Básica Conselheiro Astrogildo Odon Aguiar, na cidade de Barra Velha, SC, Brasil, com 40 alunos do $3^{\circ}$ ano do Ensino Médio noturno e quatro licenciandos do curso de letras que eram orientados pela professora de Língua Portuguesa da turma, bolsista do programa PIBID. Os estudantes do Ensino Médio possuíam computador. Foram realizados 71 encontros, de 40 minutos cada, durante 12 meses.

O marco inicial foi a leitura do romance policial Grau 26, de Anthony E. Zuiker, com o objetivo de exemplificar como uma obra do meio impresso pode abrir-se para outras possibilidades de leitura, fazendo uso de recursos multimídias. ${ }^{1}$ Grau 26 é uma publicação impressa, uma narrativa que se expande por meio de intertextos que levam o leitor a outros textos em meio digital. Uma experiência que evidenciou o conceito de intertextualidade, como a conexão de um texto a outro, princípio básico de expansão que forma uma rede de correlações entre os textos. A intertextualidade é entendida como o resultado de um embricamento de textos por meio de imitações, paródias, citações, plágios, traduções, reminiscências, paratextos, pastiches, alusões, críticas, paráfrases, entre outros, conforme aponta Genette (1982). Grau 26 é um romance que apresenta, de forma explícita, a remissão a outros textos, como podemos observar a seguir.

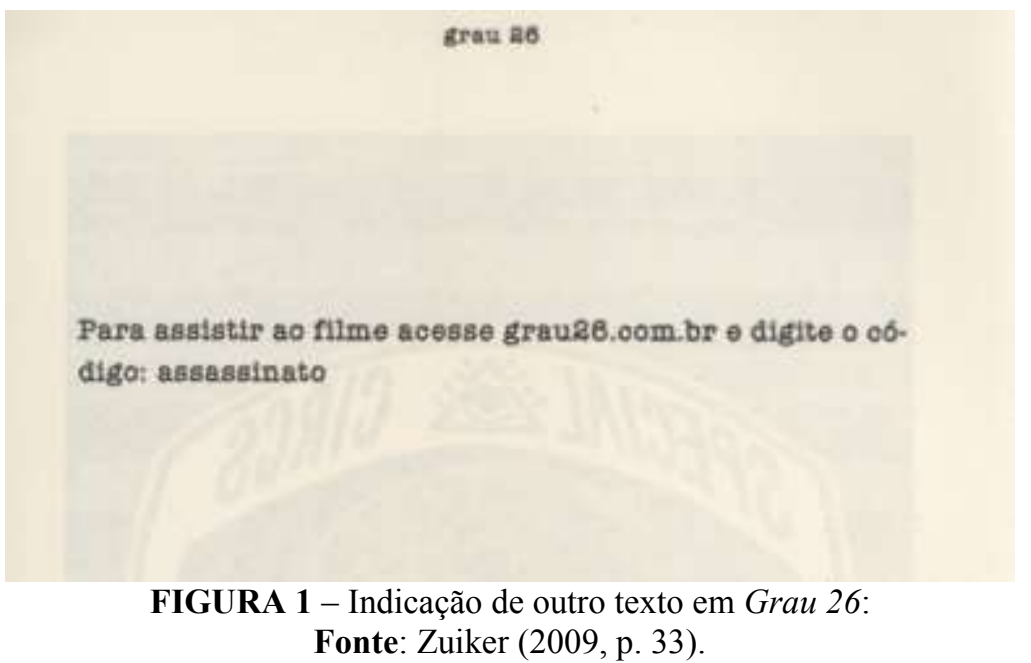

Sabemos que a remissão a outros textos e a outras linguagens, visuais ou sonoras, não é uma experiência nova. O jogo da escrita corrompe a estrutura "aparente" da linearidade do texto como fez Julio Cortázar, em $O$ jogo da amarelinha (1963), Ítalo Calvino, em Se um viajante numa noite de inverno (1979), Milorád Pavitch, em O dicionário Khazar (1984). Ao romper fisicamente com as estruturas lineares da narrativa e dirigir o leitor para leituras que estão fora da estrutura física do livro, o autor exemplifica como o suporte em meio digital pode fazer uma interlocução com outros suportes, como o livro impresso e vice-versa.

${ }^{1}$ Todos os passos do projeto de leitura e produção aplicado pelos bolsistas do PIBID encontram-se no Apêndice A, ao final deste texto.

\begin{tabular}{l|l|l|l|l|l|l} 
(C) ETD - Educ. Temat. Digit. & Campinas, SP & v.18 & n.3 & p.719-735 & jul./set.2016 & ISSN 1676-2592
\end{tabular}


Grau 26 foi a leitura selecionada para introduzir o conceito de intertextualidade, assim como para discutir como o livro impresso pode fazer uso de outras mídias, seja o vídeo, a Internet ou outra. Sua escolha deu-se também porque a escola vem priorizando leituras literárias menos incômodas, lineares e, por isso, a escolha de uma obra que, de forma aparente, encaminha o leitor para outros suportes de leitura, buscando desacomodar os leitores. Um romance do gênero policial, que não foi objeto de leitura na íntegra, empregada para exemplificar o processo rizomático do texto que vai se abrindo a cada link. O encontro com esse romance impulsionou o grupo a buscar outras leituras, de outras narrativas que possuíam dinâmicas análogas, mas em outros suportes, até a descoberta da primeira narrativa brasileira publicada na Internet, Tristessa ${ }^{2}$, de Marco Antonio Pajola.

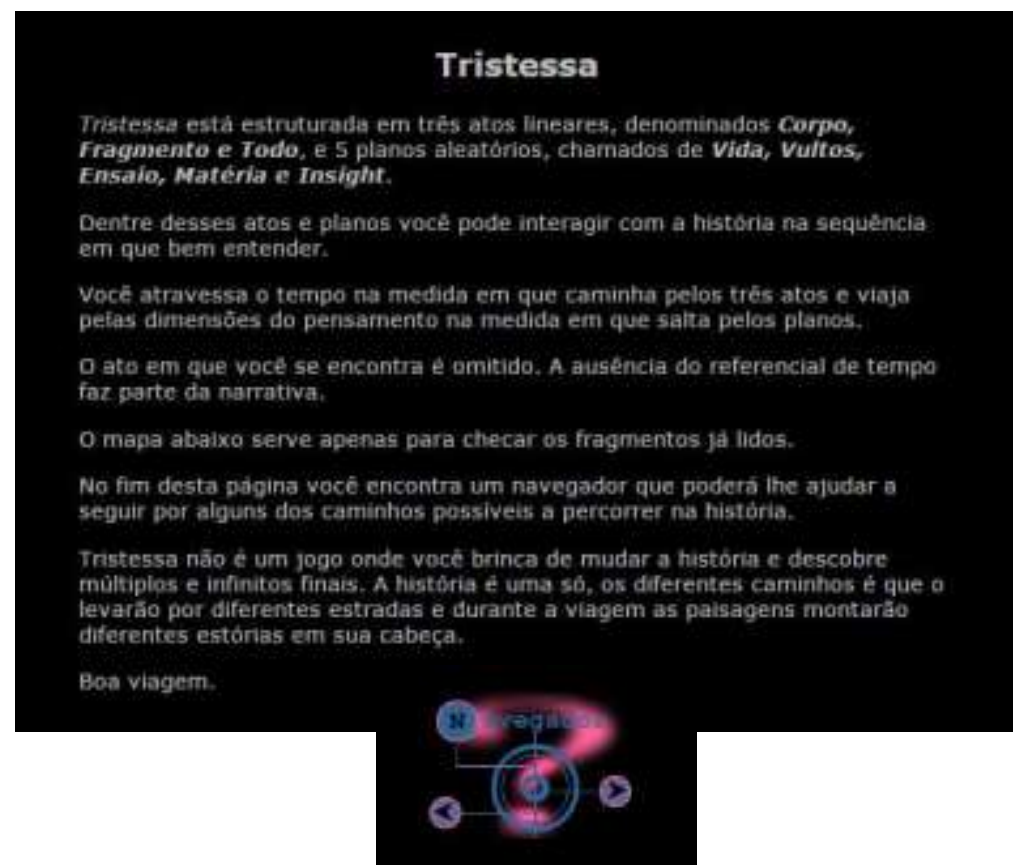

FIGURA 2 - Estrutura da obra Tristessa Fonte: Pajola (2011).

O desafio proposto foi a leitura de Tristessa pelo grupo envolvido na pesquisa. Atividades de leitura na tela do computador foram planejadas, bem como leituras sonoras e silenciosas e ao final um seminário para trocar impressões de leitura. Além da leitura na tela, foi proposto ao grupo a produção de uma narrativa em meio digital, de autoria coletiva, tecida por várias mãos e com diversos intertextos. O contato com a obra Grau 26 deu ao grupo a possibilidade de compreender o conceito de intertextualidade e de entender como as mídias podem completar-se independentemente do aparato usado, contribuindo para a abertura da obra, para uma estrutura de texto em rede, aberto a interferências diversas. Do livro ao écran, o duplo desafio insinua-se: a leitura e a produção em meio digital.

2 Tristessa é uma publicação em meio eletrônico a qual pode ser encontrada no seguinte endereço: <http://goo.gl/Qyc6d>. Acesso em: 24 mar. 2014. A obra possui, segundo o autor, "três atos lineares" - Corpo, Fragmento e Todo -, e cinco "planos aleatórios" - Vida, Vultos, Ensaio, Matéria e Insight. 


\section{A LEITURA NO ÉCRAN: A RELAÇÃO DO LEITOR COM A OBRA EM MEIO DIGITAL}

Autor (Ano: 214), ao analisar a narrativa digital Tristessa, afirma que sua estrutura é uma radícula ou arborescente, “(...) pois as páginas parecem dipolos-unidades ou dipolos-deligação, como galhos-raízes, possuindo um sistema central". Para a pesquisadora, Tristessa está distante de ser um texto rizoma, pois, mesmo o texto apresentando vários links, eles apontam sempre para o mesmo tronco, um centro regulador que mostra todas as posições e pontos da rede, o que diminui a mobilidade do leitor, visto que não há diversos pontos de entrada, há uma certa ordem na leitura e nem todos os pontos interconectem-se, "os pontos do texto não possuem o mesmo poder de conexão e não formam uma cadeia de informações sucessivas" (Autor, Ano: 184). Não há no texto botões ocultos, armadilhas que possam sustentar a ideia de estrutura dinâmica e fluída com a qual, normalmente, relacionamos a ciberliteratura.

Mesmo com essas limitações, podemos afirmar que a leitura de Tristessa na tela do computador introduz o leitor, por meio dos links, a várias outras histórias, todas encadeadas, convidando-o a interromper a leitura da narrativa central e aventurar-se por outras histórias. Nesse sentido, pela presença dos links, é uma leitura que se realiza por saltos e rupturas, e a leitura ocorre, assim, de forma fragmentada. Para o leitor pouco acostumado com narrativas não lineares, essa exige uma nova postura frente ao texto. Este outro espaço de escrita e este novo aparato, a tela do computador, são promotores de novas relações afetivas e cognitivas.

Na primeira experiência do grupo de alunos do Ensino Médio e da professora de Literatura com a ciberliteratura, os alunos leram o texto na sala informatizada da escola, que têm 20 computadores, complementados com notebooks, para viabilizar a leitura individual. Tendo em vista a necessidade de autonomia do leitor frente aos links, que poderiam ou não ser consultados, a leitura individual e silenciosa foi priorizada. Esta, segundo Cavallo e Chartier (2001), foi a grande transformação que a imprensa introduziu nos hábitos de leitura, a verdadeira revolução no ato de ler. No silêncio dos livros os leitores são forjados. É no silêncio que ocorre a emancipação do leitor e dos livros, pois é nessa relação meditativa que o leitor atinge a profundidade da leitura. Uma estratégia de leitura antiga em um suporte novo.

Da leitura silenciosa e individual na tela do computador, passou-se à leitura em voz alta e em grupo no projetor multimídia, na sala de aula. Enquanto liam, os links que o texto contém foram descortinados e a navegação nas novas páginas desvelando brechas e dobraduras textuais. A leitura em voz alta é sempre um convite para a escuta, para a partilha. A visão recebe o reforço que vem da voz. Ela possibilitou ritmo ao texto e despertou maior interesse pela obra. É bom lembrar que, para um público que não é leitor, a leitura em voz alta - ao exigir do sujeito performance por meio da entonação da voz -, convida os pares a debruçar sobre o texto e promove leituras de encontros. O texto passa a ser percebido também pelos ouvidos e a leitura projeta no outro um convite. Conhecer o texto pela voz do outro pode levar o leitor a “(...) retomar a história, lê-la sozinho, e passamos a ter a coexistência do texto oral e do escrito. Em ambas as práticas, de ouvinte e de leitor, o sujeito lida com suas 
emoções, seu comportamento e a prática poética passa a precisar uma emancipação da linguagem e do sujeito" (NEITZEL; CARVALHO, 2014, p. 7).

Os encontros de leitura na sala informatizada com práticas em voz alta e silenciosa provocaram avaliações críticas associadas às competências leitoras do grupo, reafirmando as avaliações de Burgos (2011) sobre o texto oral, como portador de um polimorfismo que interroga o lugar da oralidade em uma sociedade letrada que cultua a escrita. A leitura em voz alta é uma atividade social e, por isso, foi e ainda é hoje uma forma de democratizar a prática da leitura, de introduzir a leitura na vida das pessoas. Ela propicia ao leitor uma aproximação fácil com o texto, “(...) une puissance d'interpellation qui le rend proche et sensible" (BURGOS, 2011, p. 189), uma energia que se diferencia da leitura silenciosa e solitária exige adensamento no texto e um pacto de entrega entre sujeito e objeto. Sobre essa estratégia, Jean declara: "Je pense que la lecture à voix haute réapprise et bien conduite, en accompagnant la lecture de la présence physique, sensuelle d'une voix humaine "vive", c'està-dire corporellement vivante, féconde et redonne tout son précieux sens aux lectures solitaires et silencieuses." (JEAN, 1999, p. 114). Além da leitura em voz alta, uma prática recorrente no contexto escolar foi experienciada: a leitura na tela, em um contexto renovado pela tecnologia, aumentando, assim, o interesse do leitor jovem. Partilha de sentimentos e emoções que promovem outras relações leitoras, conforme relato da aluna a seguir.

"Ler Tristessa foi para mim inusitado, diferente de todas as obras literárias que já li, principalmente por ser uma obra em meio eletrônico... Tristessa foi uma descoberta única, da qual jamais imaginei ler, uma escrita atual, jovem... Confesso que estranhei algumas partes da história pelo seu linguajar descontraído...” (Aluna H.).
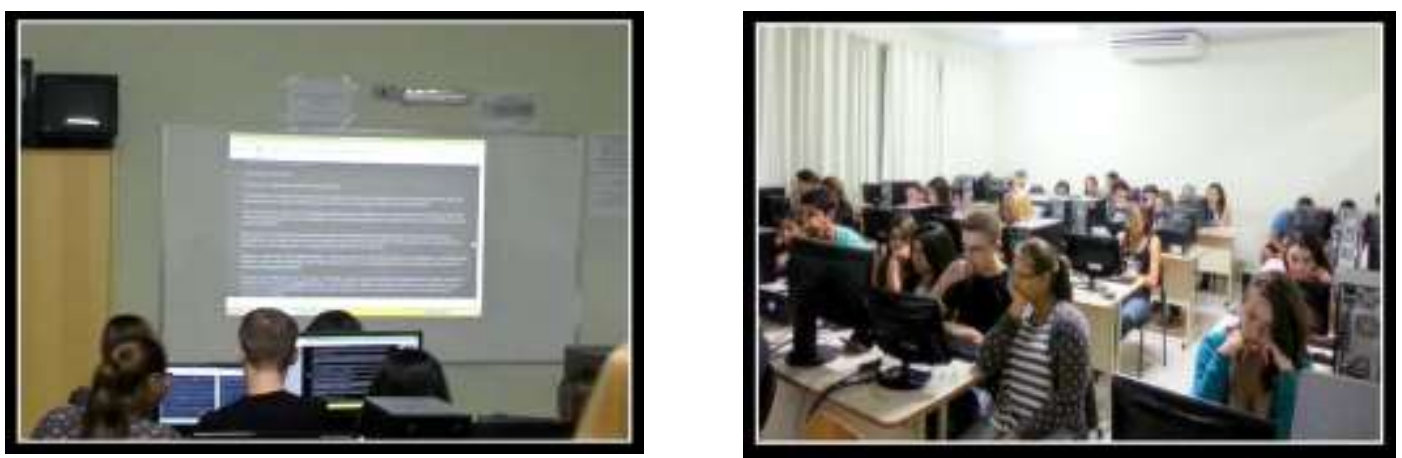

FIGURA 3 - Leitura na tela

Fonte: Portfólios dos bolsistas do PIBID.

As competências de leitura exigidas aos alunos que prestam o Sistema de Avaliação da Educação Básica (SAEB) são analisadas por Bridon (2013) que afirma que os resultados dessas avaliações sinalizam que os alunos estão abaixo do nível esperado em leitura, e que há a necessidade de os alunos lidarem com textos mais longos e mais complexos para diminuir essas fragilidades. Segundo a pesquisadora, 45,95\% dos alunos do $5^{\circ}$ ano do Ensino Fundamental, $73,04 \%$ do $9^{\circ}$ e $70,8 \%$ dos alunos do $3^{\circ}$ ano do Ensino Médio estão abaixo do nível esperado. 
Nossa hipótese sustenta que uma prática regular de leitura de obras em meio digital, na escola, resultará na aquisição de competências leitoras, visto que um hipertexto provoca alterações nas condutas do leitor. A leitura do hipertexto requer que o leitor estabeleça um percurso por vários intertextos, que estabeleça conexões entre esses textos, que deslize de um link a outro, fragmentando o processo de leitura, o que exigirá dele maior concentração para reunir os dados dispersos ao longo do texto.

"Posso dizer que entendi a obra em alguns pontos pelo fato dela não ser um obra linear, onde todos os fatos geram uma abordagem mais complexa e com maior riqueza de detalhes - isso gera uma confusão ao entendimento da obra." (Aluno O.).

Essa era de mutação de leitura sobre a qual adentramos que desestabiliza a noção clássica de narrativa e de autor pela fragmentação em meio digital é defendida por Bon (2011), Bélisle (2011) e Poulain (2012). Os pesquisadores ressaltam as potencialidades da leitura em meio digital, principalmente por essa diluição da narrativa em outros links os quais são camadas superpostas e que exigem do leitor um processo de leitura aos saltos. Essas informações disponíveis nos links, como signos que ultrapassam a linguagem verbal, engendram novas cadeias semióticas e podem levar o leitor a construir diferentes signos geradores de ressignificações.

Essa experiência de leitura na tela - realizada na sala de informática, nos computadores pessoais dos alunos e em Datashow -, foi compartilhada por meio de um seminário organizado a fim de que eles pudessem revelar suas descobertas acerca da fábula narrativa e ampliar o diálogo sobre essa vivência. A literatura ainda é percebida pelo grupo como representação de uma vida ideal e não cotidiana, mostrando fragilidade no campo do repertório literário e a necessidade de ampliar o contato com a literatura contemporânea. A motivação do leitor frente a um texto que não possui familiaridade, cuja novidade está sendo desvelada, pode também impulsionar à descoberta, como declara a aluna T:

\footnotetext{
"A leitura virtual nos permitiu desbravar novos horizontes na literatura, pois Tristessa fugiu ao que estávamos acostumados a ler. A obra abordou também temas que me chamaram atenção e elevaram a minha imaginação durante a leitura. $O$ fato de poder ir clicando em links que mostram imagens e complementam a historia é incrível, o que infelizmente só acontece a partir da leitura virtual." (Aluna T.).
}

A leitura fragmentada, por meio da inserção de links no texto, foi apontada como um ponto que desfavorece a compreensão do texto porque dispersa o leitor da trama narrativa. Segundo Beiguelman (2003, p. 23): “Ao clicar nos links, o leitor não sai do lugar, porém promove um novo arranjo da composição, alterando o conteúdo dos parágrafos e abrindo as frases a novas sequências". O texto vai, por meio dos links, se expandindo, desdobrando os fatos narrados.

"Ler Tristessa foi muito interessante, porém muito confuso, pelo fato de ser um hipertexto, pois quando achava que estava terminando, sempre tinha um link que levava a outro texto." (Aluna K). 
"No começo achei meio estranho, diferente, fiquei um pouco perdida, pois estávamos lendo em uma página e no meio do texto tinha um link que levava para outro texto (...)." (Aluna M.).

Para Donnat (2012), não lemos um texto no computador da mesma forma que lemos no livro. A leitura de hipertextos permite uma leitura aos saltos, fragmentada, descontínua. A vertigem dos alunos diante de um texto que apresenta bifurcações, causando rupturas na leitura, encaminhando o leitor para a leitura de textos periféricos, prolongando a narrativa, introduz um novo conceito de enredo, composto com vários cortes no tempo e no espaço, que não obedece mais a causalidade e a sequencialidade. A sensação de ler um texto na tela que oferece fugas de leituras por meio dos links exige do leitor disposição para “(...) opor-se à tentação de ler na ordem em que nós, da cultura ocidental, fomos alfabetizados, da primeira à última página, da esquerda para a direita, de cima para baixo" (NEITZEL, 2009, p. 174).

\section{A PRODUÇÃO DE TEXTOS LITERÁRIOS NO AMBIENTE GOOGLE DOCS}

Com a escrita em meio digital, a forma de ler também mudou. Não que a interação com os textos digitais exija ou promova competências que não sejam desenvolvidas pela leitura feita no suporte de papel. Ao contrário, concordamos com Belisle que interagir " (...) avec des textes numériques, c'est mettre en oeuvres des compétences qui s'enracinent encore principalement dans l'expérience de la lecture sur papier" (BÉLISLE, 2011, p. 10). Escrever um texto em meio digital de forma a estrelá-lo com vários outros textos é diferente de escrever um texto em meio impresso, ainda que seja uma experiência como a de $O$ jogo da amarelinha de Julio Cortazar. Tanto a produção como a recepção são alteradas. Por isso, a proposta de leitura projetada pelos licenciandos bolsistas do programa PIBID era de que os alunos (sujeitos de pesquisa) lessem e produzissem hipertextos, para que eles realizassem uma experiência nova no âmbito da leitura e da produção de textos literários.

Na etapa anterior à produção escrita, foi proposta a leitura de alguns contos do livro Cidade Ilhada de Milton Hatoum para que os alunos pudessem observar a estrutura de um texto narrativo impresso. A estratégia leitora adotada foi a leitura silenciosa seguida de debate interpretativo. $\mathrm{O}$ desafio era não apenas construir uma narrativa em grupo, mas produzir um texto multimídia.
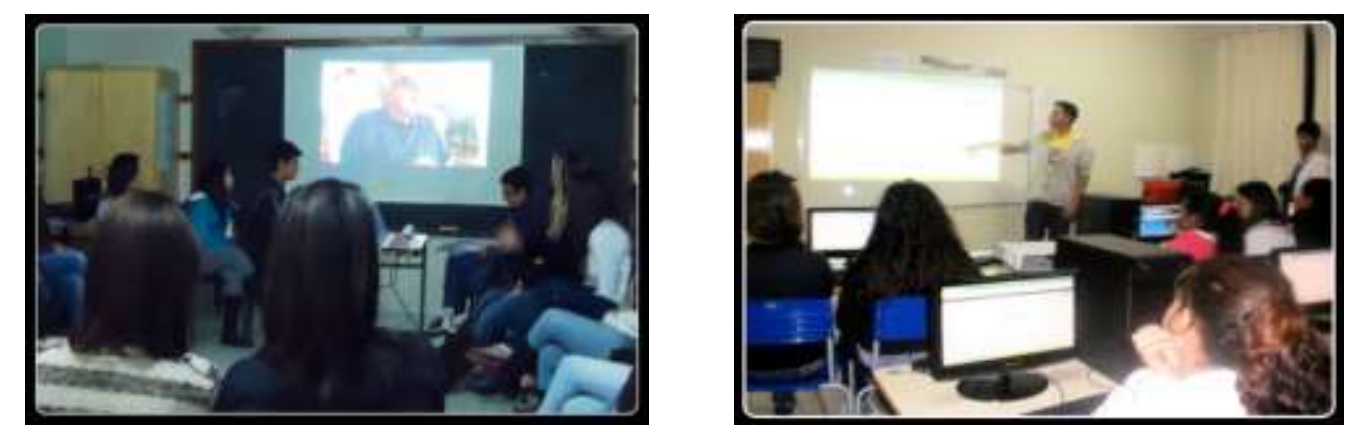

FIGURA 4 - Etapas da produção: pesquisa de textos multimídias e estudo sobre o Google Docs 
Fonte: Portfólios dos bolsistas do PIBID.

Bélisle (2011, p. 9) sinaliza que: "Lire de la littérature numérique, c'est entrer dans um nouveau contrat de découverte, d'inventivité et d'action". Um contrato que propicia aos estudantes aprender a utilizar novas ferramentas de produção e compartilhamento de texto, como o Google Docs. Essa ferramenta foi selecionada porque permite uma autoria coletiva, pois todos acessam o documento ao mesmo tempo, podendo interferir no processo de escrita dos pares. Como procedimento metodológico, a classe foi dividida em oito grupos com 5 alunos cada um, que desenvolveram as seguintes atividades:

> escrita de dois contos;

$>$ pesquisa de textos verbais para estrelar os contos produzidos por meio de links;

$>$ pesquisa de imagens que dialogavam com o texto criando assim novos links;

$>$ pesquisa de vídeos que pudessem ressignificar o texto produzido.

Esse planejamento permitiu que a classe produzisse duas narrativas estreladas por meio de links que dialogavam com outros textos, verbais e não verbais, em um estilo arborescente, com um centro regulador. Esses textos - imagens, vídeos e textos verbais - eram conectados às narrativas criadas com o intuito de expandir as possibilidades de ressignificação da obra. O processo de produção de textos multimídias em grupos possibilitou que os alunos percebessem:

$>$ como um texto se compõe em diálogo com outros textos, em um processo intertextual;

$>$ que a leitura e a pesquisa estão no centro do processo de escrita;

$>$ como se dá o processo criativo;

$>$ como desenvolver um texto de autoria coletiva, dialogando com os colegas, trabalhando em equipe e negociando saberes;

$>$ a importância da revisão no processo de produção de textos.

Trabalhando no Google Docs, os estudantes vivenciaram o processo de produção de um texto coletivo que resultou na construção de duas narrativas: Como se fosse verdade e $O s$ mistérios do reencontro. A finalização da narrativa sinalizou o início de uma nova etapa: o estrelamento do texto por meio da inserção de links que expandissem a narrativa ao se abrir para novos textos, imagens e vídeos. Dessa forma, essa atividade permitiu uma troca de opinião entre os pares, de informações pessoais, de fotografias, vídeos, textos, etc.

\footnotetext{
"O legal mesmo foi poder produzir um texto baseado em Tristessa. Admito que foi um trabalho em grupo muito gostoso de se realizar, aprendemos a compartilhar e respeitar ideias e opiniões (...).” (Aluna C.).
}

"Ter a oportunidade de criar uma história foi esplendido, é como se você estivesse
vivenciando tudo aquilo que estava escrevendo, as palavras, as ideias vão surgindo
com naturalidade, não dá vontade de parar (...)." (Aluna H.).

"Fugindo da leitura comum e desfrutando de uma diferente, porém divertida leitura." (Aluna N). 
"Foi com bastante gozo que participei da formação dos links de texto, onde tive a oportunidade de conhecer mais afundo o que é um hipertexto. (...) aprendendo dia após dia assuntos jamais imagináveis. ”(Aluno G.).

"O projeto foi muito bom, bem diferente, divertido, onde tivemos que realizar os links de imagens, foi bem diferente do que éramos acostumados a fazer, gostei muito." (Aluna P.).

"A vontade de escrever e produzir foi maior, estive no grupo da produção textual, fiquei tão envolvida e empenhada que passei a gostar ainda mais da leitura, estou até pensando em meu próprio livro." (Aluna L.).

A narrativa construída deixa de ser um decalque de vários textos, verbais e não verbais, pois a sua junção convida o produtor do texto a estabelecer elos entre eles em um processo de montagem. A vivência deste duplo movimento - de cortes temporais e espaciais, mas também de reunião das partes constituintes do todo -; propõe ao grupo a experiência de ouvir o outro, de buscar entender sua opinião. A criação de um produto que é composto por várias mãos e por um conjunto de texto também causa desconforto, mesmo aos jovens que estão mais familiarizados com a tecnologia:

\footnotetext{
"A experiência de construir um texto foi boa, porém, tive dificuldades na produção de links, pois dar continuidade a uma história produzida por outro grupo, realmente foi trabalhoso." (Aluno K.).

"Não gostei de Tristessa, não é um gênero que eu gosto, mas a ideia do autor foi boa de fazer em hiperlink". (Aluno J.).
}

Contudo, à dificuldade desse processo são arrolados os benefícios que as descobertas oferecem indicando o movimento de aprendizagem no qual todos estavam envolvidos.

\begin{abstract}
"Confesso que tive um pouco de dificuldade, pois foi difícil ouvir, entender cada opinião, cada ideia dos integrantes do meu grupo para podermos acrescentar, de certa forma, todas essas ideias na nossa história. Mas foi muito gratificante poder trabalhar em equipe, pois assim aprendi que pensamentos diferentes podem dar certo". (Aluna A.).
\end{abstract}

Bellanger (2011) compara a Internet a um oceano, pois ambos promovem a ligação universal entre os continentes e possibilitam que pessoas se encontrem, dando a elas liberdade de mobilidade. No passado, o controle marítimo mudou a história do mundo e, hoje, a Internet, com sua constituição em rede, rompe barreiras ao manter a humanidade conectada. Segundo o autor, é esta a mais poderosa alavanca de emancipação individual e coletiva moderna. "Le réseau donne à chacun la possibilite de contribuer, de créer, d'aider les autres comme jamais auparavant.” (BELLANGER, 2011, p. 153).

Várias são as formas de sociabilidade que a Internet propõe. Ferrand (2012), ao discutir sobre a diversidade dos usos da mídia, pontua que em uma perspectiva de uso público ela comporta quatro componentes principais: a) o político, centrado na informação; b) o divertimento; c) a publicidade comercial; e) a expressão pública dos sujeitos. Tendo em vista esse potencial de expressão pública da Internet, que, segundo Ferrand (2012), vem ao 
encontro de um ardente desejo do homem contemporâneo, os estudantes do Ensino Médio passaram a utilizar a rede para publicar seus dois contos:
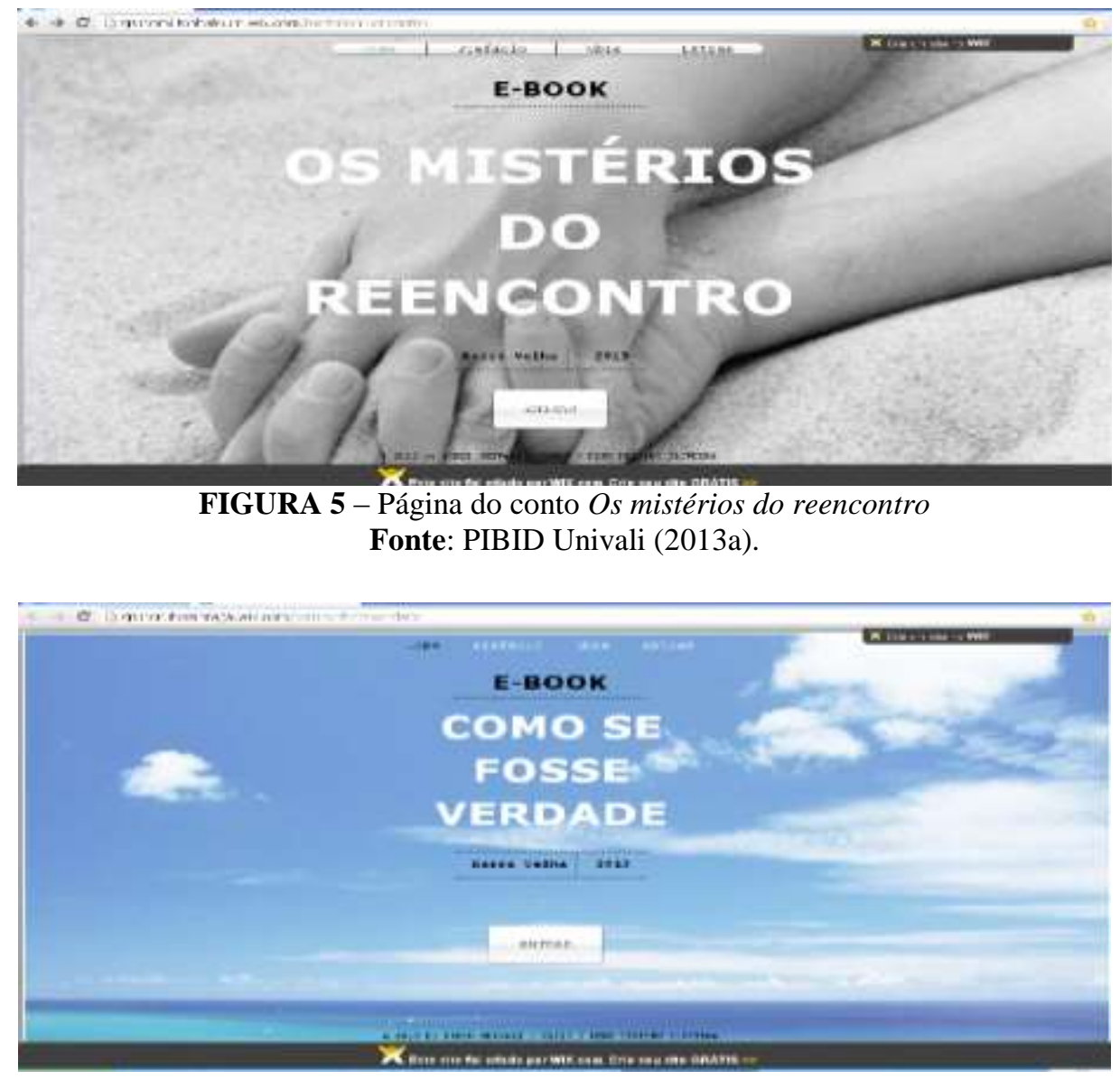

FIGURA 6 - Página do conto Como se fosse verdade

Fonte: PIBID Univali (2013b).

A participação nessa atividade de leitura e produção de textos mobilizou o grupo, movimentou-os à criação de textos que pulsam, vibram e emocionam. Constatamos que esse grupo, cuja maioria não tinha hábitos de leitura, viveu uma experiência literária que o tocou, atraiu, afetou, que o convidou a ver o texto literário em outra ótica. O que tornou a atividade tão dinâmica? Na função de leitores e de escritores, os alunos descobriram possibilidades de leitura e produção em meio digital. Para Donnat (2012), as jovens gerações manifestam um interesse crescente pelas novas formas de narrativas e suas referências são cada vez mais aquelas que exploram as tecnologias tais como a televisão, o vídeo game, o cinema e produções multimídias, entre outras. Essa imersão do jovem nas tecnologias não pode ser vista, segundo o pesquisador, sem consequências no campo da leitura, pois sua capacidade de ler é afetada assim como seu imaginário.

Vivemos a cultura da imagem, da tela. Além disso, todas as tecnologias intelectuais assim como as operações de produção modificaram-se. Essa atividade de produção de textos literários em um suporte multimídia exemplifica como as operações de produção foram alteradas. A autoria coletiva tornou-se necessária na produção de um hipertexto tendo em vista a diversificação de textos e recursos empregados. De fato, os jovens hoje dispõem de 
acesso ao mundo sem a mediação da família e dos professores e, muitas vezes, os papéis são invertidos - a informação também caminha no sentido da juventude para a família ou para a escola, uma situação que mostra que foi deposto o seu monopólio. Bélisle (2011, p. 27) afirma que “(...) les enseignants et les chercheurs perdent du terrain dans l'établissement des standards pour apprendre et pour la validation des connaissances".

O exercício de leitura e escrita em meio digital, portanto, permite que os leitores mudem sua percepção de literatura e a interpretem pelo viés da imaterialidade cultural. Uma aprendizagem de leitura e escrita compartilhada e, por isso, a turma organizou o lançamento do conto no site, e, concomitantemente, apresentaram uma leitura dramática de um conto produzido de forma coletiva a todos os alunos do turno noturno. Essa atividade de leitura e de escrita teve uma dimensão lúdica e cultural, mas, sobretudo, produziu ressonâncias na percepção dos leitores sobre o texto, sobre as relações intertextuais que podem ser produzidas tanto pelo escritor como pelo leitor e, por isso, não podemos deixar de mencionar sua dimensão de aceder ao conhecimento e à cultura. Para Petit (2008, p. 37), “(...) o escritor e o leitor constroem-se um ao outro; o leitor desloca a obra do escritor e o escritor desloca o leitor, às vezes revelando nele um outro, diferente do que acreditava ser".

\title{
5 CONSIDERAÇÕES FINAIS: PERCEPÇÕES SOBRE O PROCESSO
}

\author{
Novos tempos, novas expectativas. (...) Sou de uma família bastante humilde que \\ não sabe ao menos o que é computador, quando mencionei o livro em meio digital \\ eles espantaram-se (...). \\ Aluna L.
}

Esse projeto foi desenvolvido em uma escola pública, cujos alunos/leitores fazem uso do computador, na sua maioria, mas não para fins de leitura do literário, mas principalmente para uso das redes sociais. Entretanto, o depoimento da aluna na epígrafe evidencia como o emprego do computador para a sua família não faz parte de sua vida e que a ciberliteratura ainda consiste em uma novidade. Se Benhamou (2012, p. 96) sinaliza a necessidade de pesquisas sobre as condições de recepção de livros em meio digital, esta pesquisa aponta evidências da necessidade de a escola ampliar o uso de diversos meios de difusão e de produção de textos nos projetos de formação de leitores.

O projeto Leitura e produção em meio digital possibilita-nos descortinar a literatura online como estratégia de leitura a ser incluída nas práticas de formação de leitores, pois os depoimentos dos participantes demonstram interesse e gosto pela leitura e, também, pela escrita, por serem feitas em um ambiente dinâmico, que oferece várias ferramentas para a produção de uma história. Um movimento positivo de mediação instaurou-se nas aulas de Língua e Literatura e os alunos deixaram de ler e escrever apenas no papel e passaram a utilizar também o computador para leitura e produção de textos. Além disso, os estudantes aprenderam a lidar com a quantidade enorme de informações que a Internet disponibiliza, selecionando, analisando, questionando, avaliando o que os permitiu serem mais participativos nas aulas. 
Esse percurso permitiu-nos perceber que o trabalho com a ciberliteratura provocou, inicialmente, um estranhamento, uma vez que esse não é o uso comum feito pelos estudantes. No entanto, ao mesmo tempo, ao fazerem práticas de leitura literária concomitantemente em meio virtual e meio impresso, levou os alunos à apreciação estética do texto literário nos dois formatos. 'La connaissance ne se réduit pas à de l'information transmise ou acquise. C'est la prise de conscience et la compréhension de faits, de vérités ou de croyances résultant de la perception, de l'apprentissage et du raisonnement." (BÉLISLE, 2011, p. 32).

Além disso, no âmbito da escrita, houve por parte dos envolvidos o reconhecimento da complexidade do processo de produção textual, seja ela no formato digital ou impresso, que sempre é calcada na intertextualidade. Ainda, o movimento de produção de textos coletivamente, com convergência de várias mídias, com um grande universo de informações exigiu o desenvolvimento de várias competências leitoras. Enfim, a vivência durante um ano letivo com uma outra maneira de ler, de escrever e de relacionar-se com o texto e com o outro ampliou a vivência estética dos envolvidos e sua percepção sobre o processo de escrita e de leitura.

Muitas mediações foram efetuadas e elas sinalizaram a oportunidade de os alunos fazerem descobertas, possibilitando a "(...) mobilidade nos acervos e oferecendo conselhos eventuais sem pender para uma mediação de tipo pedagógico” (PETIT, 2008, p. 175). Os encontros de leitura e de produção propostos promoveram a aproximação dos envolvidos, e, a partir de diferentes estratégias - meios e recursos, partilha, diálogo -, o desejo pelo texto foi aumentando. Esse processo nos revela o importante papel do professor na mediação do processo de leitura. "É por identificação com este leitor magistral que é o professor que começo a sentir as emoções do livro que, mais tarde, vou reviver na releitura como adulto." (CHARTIER, 1999, p. 2).

\section{REFERÊNCIAS}

BARTHES, Roland. Aula. São Paulo: Cultrix, 2002.

BON, François. Après le livre. Paris: Ed. du Seuil, 2011.

BEIGUELMAN, Giselle. O livro depois do livro. São Paulo: Petrópolis, 2003.

BÉLISLE, Claire. Du papier à l'écran: lire se transforme. 2011. Disponível em: <http://goo.gl/dqWaTL>. Acesso em: 15 fev. 2016.

BELLANGER, Pierre. De la souveraineté en général et de la souveraineté numérique en particulier. 2011. Disponível em: 〈http://goo.gl/gQr67s >. Acesso em: 10 jan. 2016.

BENHAMOU, Françoise. Le livre et son doube - réflexions sur le livre numérique. Le débat - le livre, le numérique, n. 170, p. 90-102. mai./ago. 2012. Disponível em:

<https://goo.gl/cs3uXp >. Acesso em: 28 mar. 2016. ISSN 0246-2346. 
BRIDON, Janete. Entre um texto e outro, o leitor em formação. 2013. 160 f. Dissertação (Mestrado em Educação) - Universidade do Vale do Itajaí, Itajaí, SC, 2013. Disponível em: <http://goo.gl/GWbYHx >. Acesso em: 28 mar. 2016.

BURGOS, Martine. La lecture à voix haute: un rituel de partage. In: EVANS, Christophe. Lectures et lecteurs à l'heure d'Internet - livre, presse, bibliothèques. Paris: Ed. du Cercle de la librarie, 2011. p. 181-192.

CAVALLO, Guglielmo; CHARTIER, Roger. Histoire de la lecture das le monde occidental. Paris: Ed. du Seuil, 2001.

CHARTIER, Anne-Marie. A importância da escola na formação do leitor. 1999. Disponível em: <http://goo.gl/LJ9auu>. Acesso em: 17 set. 2015.

CORTÁZAR, Julio. O jogo da amarelinha. São Paulo: Círculo do Livro, 2006.

DONNAT, Olivier. Gardons-nous de trop idéaliser la lecture des temps passés. In: BESSARD-BANQUY, Olivier. Les mutations de la lecture. Bordeaux: Presses Univ. de Bordeaux, 2012, p. 39-49.

FERRAND, Olivier. La révolution médiatique de la condition humaine. Le débat - le livre, le numérique, n. 170, p. 160-174. mai./ago. 2012. Disponível em: 〈https://goo.gl/ue36eE $>$. Acesso em: 28 mar. 2016. ISSN 0246-2346.

GENETTE, Gerard. Palimpsestes: la littérature au second degré. Paris: Seuil, 1982.

JEAN, Georges. Peuple et culture: Le Club de lecture dans la lecture à haute voix. Paris: Les éditions de l'Atelier, 1999.

NEITZEL, Adair de Aguiar; CARVALHO, Carla. A movência do leitor na leitura do literário. Raído, Dourados, MS, v. 08, n. 17. jul./dez. 2014. Disponível em: <http://goo.gl/jri06K >. Acesso em: 28 mar. 2016. ISSN 1984-4018.

NEITZEL, Adair de Aguiar. O jogo das construções hipertextuais. Florianópolis: UFSC; Itajaí: UNIVALI, 2009.

PAJOLA, Marco Antonio. Tristessa. 2011. Disponível em: 〈http://goo.gl/Qyc6d >. Acesso em: 20 fev. 2016.

PETIT, Michèle. Os jovens e a leitura: uma nova perspectiva. São Paulo: 34, 2008.

PIBID Univali. Os mistérios do reencontro. 2013a. Disponível em: 〈http://goo.gl/S3L42p $\rangle$. Acesso em: 12 mar. 2016.

PIBID Univali. Como se fosse verdade. 2013b. Disponível em: 〈http://goo.gl/C3ngZ9 $\rangle.$ Acesso em: 12 mar. 2016.

POULAIN, Martine. Entretien. In: BESSARD-BANQUY, Olivier. Les mutations de la lecture. Bordeaux: Presses Univ. de Bordeaux, 2012, p. 69-83. 
SANTAELLA, Lucia. O novo estatuto do texto nos ambientes de hipermídia. In:

SIGNORINI, Inês (Org.). [Re]discutir texto, gênero e discurso. São Paulo: Parábola, 2008, p. 47-72.

SILVA, Ezequiel Theodoro da. Entrevista com o professor Ezequiel Theodoro da Silva. Dossiê Temático Leitura e formação de professores. Revista Profissão Docente, Uberaba, MG, v. 12, n. 26, p. 115-119. jan/jun. 2012. Disponível em: 〈http://goo.gl/jH6Mjz〉. Acesso em: 28 mar. 2016. ISSN 1519-0919.

STIGGER, Verônica. Gran cabaret demenzial. São Paulo: Cosac Naify, 2007.

ZUIKER, Anthony E. Grau 26: a origem. Rio de Janeiro: Record, 2009.

\section{APÊNDICE}

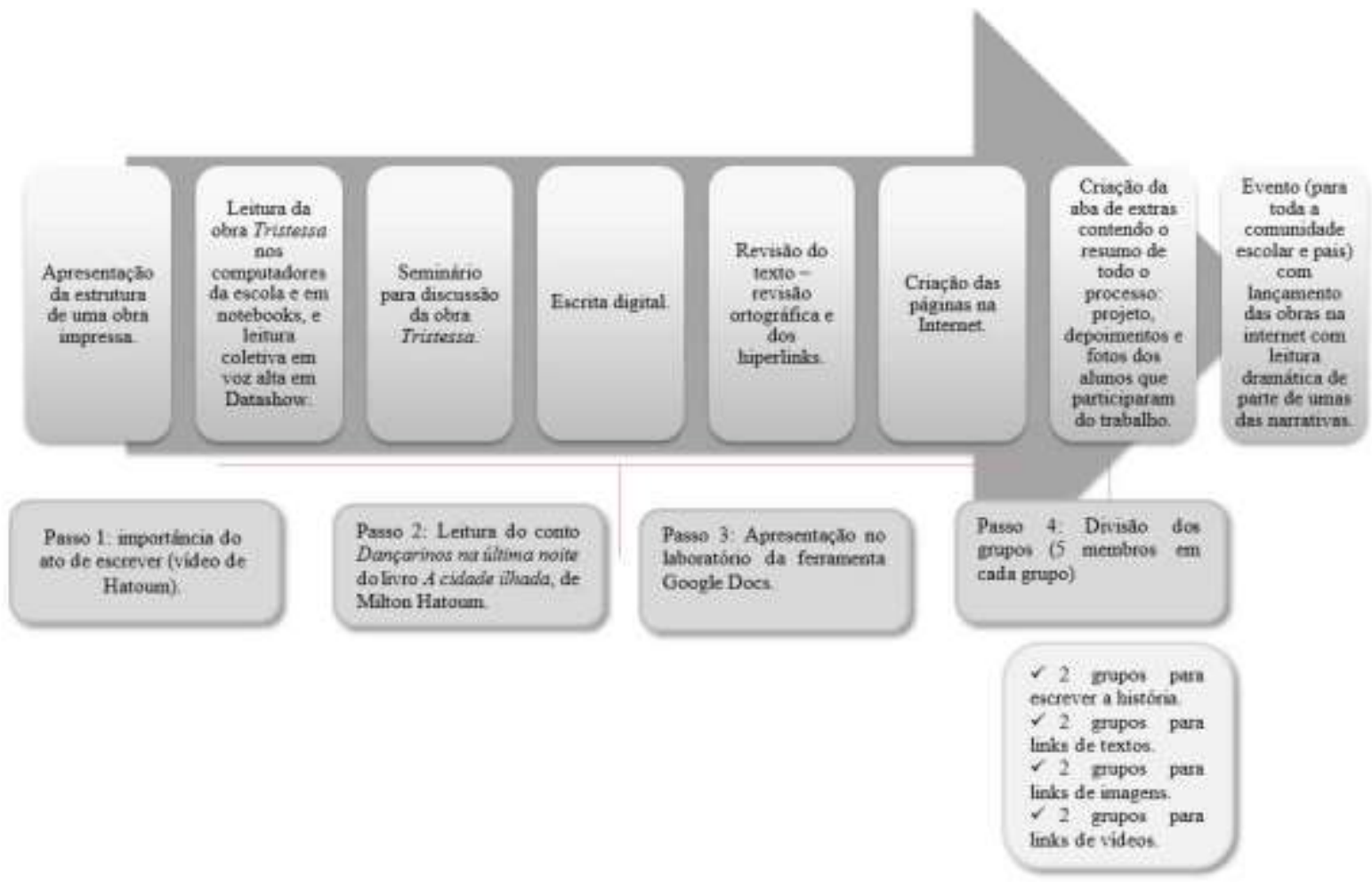

FIGURA 7 - Etapas do projeto Os desafios da leitura e produção em meio digital

Fonte: Os autores. 


\section{AGRADECIMENTOS}

Agradecemos à CAPES pelo financiamento desta pesquisa por meio do PIBID - Programa Institucional de Bolsas de Iniciação à Docência.

ADAIR AGUIAR NEITZEL

Doutora em Literatura - UFSC Universidade Federal de Santa Catarina Florianópolis, SC - Brasil

Professora da Universidade do Vale do Itajaí - UNIVALI

Itajaí, SC - Brasil - E-mail: neitzel@univali.br

TAÍZA MARA RAUEN MORAES

Doutora em Literatura- UFSC Universidade Federal de Santa Catarina Florianópolis, SC - Brasil Professora da Universidade da Região de Joinville - UNIVILLE Joinville, SC - Brasil - E-mail: moraes.taiza@gmail.com

CLEIDE JUSSARA MULLER PAREJA Doutoranda em Educação - UCSF Universidade Católica de Santa Fé - Santa Fé - Argentina Professora da Universidade do Vale do Itajaí - UNIVALI Itajaí, SC - Brasil - E-mail: cleidepareja@ hotmail.com

Recebido em: 28/03/2016 Aprovado para publicação em: 07/05/2016

\section{Como citar este documento:}

NEITZEL, Adair Aguiar; MORAES, Taíza Mara Rauen; PAREJA, Cleide Jussara Muller. A leitura e a escrita em mutação: experiências no meio digital. ETD - Educação Temática Digital, Campinas, SP, v. 18, n. 3, p. 719-735, jul. 2016. ISSN 1676-2592. Disponível em:

<http://periodicos.sbu.unicamp.br/ojs/index.php/etd/article/view/8644572>. Acesso em: 30 ago. 2016. doi:http://dx.doi.org/10.20396/etd.v18i3.8644572. 